\title{
Automobile Monitoring and Tracking System: A New Model
}

\author{
G. Kanagaraj, Priya .J, Anitha .P
}

\begin{abstract}
In addition to manufacturing, production of cars and other automobiles, theft attempts is also increasing day by day. There is a greater effort done by several industries and corporations to provide security in an automobile, but the outcome is not up-to the expected level since the count of car thefts are being increases. This research proposes a smart model for monitoring and tracking automobiles to resolve issues like theft. It proposes a security model that will send a SMS to the possessor of an automobile to give an alert immediately particularly if the automobile is near. The Database holds the essential information about the automobile and its possessor, which helps guards or authorities to track the car by using the proposed smart system that will be linked to Google Maps. The temporal arrangement and outcome are appropriate to the possessor and the guards to require appropriate action against a thief.
\end{abstract}

Keywords - Automobile, Google Maps and Communication Protocol

\section{INTRODUCTION}

Now-a-days, the amount of automobiles is increasing so fast in numbers which allows an attempt by a thief. The loads of automotive security systems that had been made delay; however, the results still not satisfied because the range of cases is being increased. A thief's stealing techniques are stronger and cleverer that requires highly secure systems. One of the statistics shows that $96 \%$ of the general people are not clued to after they discern associate degree alarm. In addition to that, statistics also shows that the alarm indication alone doesn't contribute a lot in preventing an automobile theft. The existing automobile theft alarm system does not cover large areas [1]. The Interpol statistics [2] shown that automobile theft is an extremely systematized vicious activity affecting the entire world. The automobiles are not solely stolen for the person's personal use; generally they peddled to finance some other equivalent crimes. They even used as explosive material carriers or within the commission of alternative issues [2]. The Secretariat of Interpol framed a database called ASFSMV to provide required information to police in the case against vehicle trafficking and theft. In the statistics, until December 2009, around 6.2 million records of stolen automobiles were in the database. Near 151 countries use the information often, among them 123 countries given their records of a stolen vehicle to INTERPOL.

By the analysis made on automobile thefts since previous years, we come across with few points to be noted and highlighted. It proves that, in Malaysia for every hour, 8 vehicles were stolen and annually only less than $30 \%$ were recovered. Some fashionable cars are being stolen, and also some luxury cars like Toyota Harrier, Mercedes and BMW even $[4,5]$. Those cars may get exported any other places either as break into parts or rearranged and sell it for local criminals or somewhere else, or as a full unit. There are so many ways to steal automobiles like cars, the most common way is breaking the glass windows of the car and unlock the door, using ruler like material and inject it between the window glass and rubber lining at the door to unlock the central lock system and as a last trial to tow the vehicle away. Among the issues which pave the way to peddle the automobiles with an alarm circuit which is unreliable, installed in automobiles, lethargic owner and careless activities.

The analysis gives that, surplus amount of alerting system and monitoring products for automobiles are available such as: CARALL Multi-Function Alarm System with Build in Key [6], GSM based Video Alarm system [7], GPRS/CDMA based Wireless Image gear [8], The CCTV video based alert System [9], Automobile Security System through transportable [10], Autonomous Vehicle Monitoring and Tracking System [11], Vehicle Locator based on GPS/GSM/GPRS [12]. Some details also associated with parameters of a security systems and elements deployed in this paper are explained in given references [13-19]. Data analysis and the capabilities of those products are summarized [20]. To overcome the above-mentioned automobile problems, an integrated automobile monitoring and tracking model with mobility, reliability and database facilities has been proposed.

\section{PROPOSED MODEL}

Once the owner locks the car, the alarm system circuit will get initiated. Here, few sensors like magnetic and IR sensors are placed in particular places within. It may acts as a detector and when it is being triggered, it produces high voltage. If the door is open in a wrong pattern, it will detect by the magnetic door. Also activates the infrared to discover any changes within the automotive. Once the IR sensor is triggered, the PIC controller sends the signal to relay, that makes the mobile or handset to get operate. Then it initiates camera app and captures the image. In return, it sends the

\footnotetext{
Revised Manuscript Received on September 14, 2019.

G.Kanagaraj, Assistant Professor, Kumaraguru College of Technology, Coimbatore, Tamilnadu, India. (Email: kanagaraj.g.cse@kct.ac.in)

Priya.J, Research Scholar, Bannari Amman Institute of Technology, Chennai, Tamilnadu, India. (Email: priyaajothimani@gmail.com)

Anitha.P, Assistant Professor, Dr.NGP Institute of Technology, Coimbatore, Tamilnadu, India. (Email: anitha@drngpit.ac.in).
} 
images to the owner via GSM module.

Once the owner receives a confirmation message of a theft event, the mobile phone will automatically send the SMS. Receiver modem is connected to a computer which contains a database of all automobiles with the help of RS232 cable which includes automobiles color, registration number, name of the processor and also information from the GPS. The GPS receiver is fixed in the car which is for tracking purpose. Then the receiver is integrated to PIC microcontroller. The controller sends messages (SMS) to the database which is framed. Hence, the system will point the automobile's location exploitation mapping code.

At last, the management center can get back all the data required and shares to the guard's server via e-mail.

\section{A. Sensors}

There are so many sensors are available today. In this project, two types of sensors IR and magnetic sensors are used. IR sensor is an important sensor here for this automobile application for its potency, cheapest price and availability. Second, magnetic sensor which consists of two magnetic bars is coupled and placed between windows and doors. A cable is connected to the microcontroller, detects the deviation in voltage. There will be a constant current flow in the wires connected once the doors are closed due to perfect magnetic field. When the door is being opened, there will be a change in voltage. Therefore, it triggers the alarm circuit [21].

\section{B. PIC Microcontroller}

Microcontrollers are said to be low-power device, small and low cost. The components are chosen in this system is to reduce the cost, size as attainable. A controller could be a family of Harvard design microcontrollers created by semiconductor technology. The chosen controller is having more programmable memory and it provides high performance [22]

\section{GPRS/GSM Module}

GPRS and GSM units are probably used for so many wireless services. GPRS data transfer is usually charged during communication of data through a designed circuit switching is charged per minute of transmission duration, irrespective of user state of communication. GPRS are named for effective packet switched service, where the Quality of Service is assured during the transformation of data of non-mobile users [23].

\section{GPS}

GPS receiver usually receives signals from satellites. At one point, the information about the location is transmitted to a base station that will be displayed as a computerized map [24]. Modes of GPS module can be of Hot Start mode, Warm Start mode or Cold Start mode. Cold Start mode gives the longest Time-To-First-Fix (TTFF). In warm or hot start modes [27] the GPS receiver gets initiated or booting up with the help of a valid almanac. The receiver may have an "art-20"> Execution of a cold begin can mechanically lead to a replacement almanac transfer. Ephemeris information contains preciseness changes to the almanac information and that is needed for correcting the positioning in maps.

\section{E. Handset}

Here we have chosen a handset named NOKIA 3200 is one of the old models from NOKIA which has a user friendly interface. Since it is a cheaper model, it is being used in this project. And it is to be integrated with VGA camera module. Since this project designed with the advantage of cheapest price and easy to use, this mobile is integrated with a camera and also designed to be capable for supporting smart function.

\section{F. Database}

Data may be a categorized assortment of information that is framed to satisfy the requirements of a group of users. A database of a computer depends on the software to categorize the receiving data. This can be done in a structured way that already defined is what the database management system (DBMS) [25].

\section{G. Guards}

Police/ Guards helpers as a group named as RakanCop in Malaysia. The group allows the public to communicate with the guards, if they have experienced any threatens by criminal activists. The service for public is followed up on 24-hour Police Control Centre.

\section{SYSTEM IMPLEMENTATION}

The circuit of the alarm model will get initiated, once the owner locks the car. The magnetic sensor and IR sensor are placed at some defined places within the automobile. A sensor also acts as a detector and generates high voltage when they triggered. The sensors used in this proposed system will act as a detector and when it is being triggered, produces high voltage. If the door is open in a wrong pattern, it will detect by the magnetic door. Also activates the infrared to discover any changes within the automobile. Once the IR sensor is triggered, the PIC controller sends the signal to relay, that makes mobile to get operate. Then it initiates camera app and captures the image. In return, it will send the images to user via GSM module.

The confirmation can be done by the user by make a call to the handset. Once the user receives a confirmation message of a theft event, the mobile phone will automatically send the SMS. Receiver modem is connected to a computer which contains the database of all automobiles with the help of RS232 cable which includes automobiles color, registration number, name of the processor and also information from the GPS. The GPS receiver is fixed in the car which is for tracking purpose.

Then the receiver is integrated to PIC microcontroller. The controller sends messages (SMS) to the database which is framed. Hence, the system will point the automobile's location exploitation mapping code. Finally, the management center may retrieve the data required and send to RakanCop server through the e-mail. The electronic components used in the proposed model are following: 


\section{A. SMS alarm}

The project comprises of functions like detection, prevention with the benefits of sensors that are used here. For detection, IR sensor has been used in this proposed system. Moreover, the vital role of this project is the deployment of SMS alerting system. The alert message via SMS service is sent to the car possessor's handset stating that irrelevant happenings in their car.

\section{B. MMS alarm}

Objective of our proposed systems is to send pictures with the help of a GPRS module to handsets of the automobile owner. The controller sends the alert message to user by MMS service and updates the data in the database via a GPRS module.

\section{Car Security Database}

Database is framed and it plays a major role, since all the details of automobiles were stored and being updated then and there. Database is programmed using MySQL which holds the information about owners of automobiles also. The GPRS module is connected to the PC which holds the framed database, which receives the MMS from the proposed system fixed in a car already and get saved as a small data file in the format of MS-Access. Here a tiny graphical interface is programmed to deal with the GPRS module and other electronic components and also to receive the information through SMS and MMS and get stored in the database.

The delay in receiving SMS alert also can be analyzed by our proposed system and can be resolved in the future.

\section{Integration}

The proposed system has prominence on monitoring, detecting and tracking automobiles, with low cost applications. To execute the process of capturing image, the operation has been programmed in a PIC controller; also send MMS to the unit. Adding to the feature of our system, another part is GPS, which improves the tracking capability. The proposed prototype is performing in a well manner in terms of monitoring and tracking very effectively and efficiently. Another unit in the proposed system consists of MMS supportive electronic components and information.

MySQL is used to program the database which holds the information of all users and their automobiles PC which holds the framed database, which receives the MMS from the proposed system fixed in a car already and get saved as a small data file in the format of MS-Access. a tiny graphical interface is programmed to deal with the GPRS module and other electronic components and also to receive the information through SMS and MMS and get stored in the database. The SMS alert from the car will be linked with one of the mapping software to point out the exact location during any interruption.

\section{ANALYSIS AND DISCUSSION \& RESULTS}

To implement a secured system, a quick alert mechanism is needed with the fast response. Here the proposed system is using GSM module for supporting SMS and MMS services. It also supports to send an alert message to the user and also to get updated in the framed database. Delay may occur while transmission of alert messages via SMS/MMS, that was analyzed. Delay in SMS transmission can be tolerable than delay in MMS transmission. A detailed study is needed for reducing the delay in MMS transmission. Therefore, a test was conducted in an IIUM environment. The transmission delay also analyzed during busy hour $(1 \mathrm{pm}-2 \mathrm{pm})$. From the analysis report, MAXIS service provider can deliver same MMS transmission with less delay time while comparing to other service provider. Hence, a best service provider for this security system is MAXIS. Also from the discussion and analysis of this study, it shows that the average TTFF using cold start mode is 126.4s. Henceforth, the delay time has to be considered before sending the GPS data via SMS. Else the receiver gets overhead and gives wrong information about the measurement consequently.

\section{CONCLUSION}

Even though there are surplus alerting systems for automobiles, the car theft is still rapidly increasing in numbers. This proposed automobile tracking, monitoring and alerting model gives the great easy-to-implement and build the system capability. This is an efficient model, uses mobility capabilities like MMS for alerting the owner; and also data update in database part also makes this proposed model to be a successful one. Provides solutions to some related problems includes, categorizing the issues about stolen cars, alert message transmission speed, accuracy in storage of information in the database.

The results and analysis of the proposed system working model is good. The transmission of messages using MMS service between the user and database also successfully experimented. Probably it takes an average time about 40 seconds to receive an alert message by the user. This time period is more than enough for a user to reach the automobile before it gets stolen if it is nearer to his location. Database also receives the intruder image within 4 minutes through MMS service has been more useful for the security guards and police to take action against the intruder. Hence the proposed model helps to reduce the car theft cases and also supports to increase the probability of finding stolen cars.

\section{REFERENCES}

1. Laith Farhan, Ali E. Alissa, Mohmad Alrweg, Umar Raza and Rupak Kharel, "A Survey on the Challenges and Opportunities of the Internet of Things (IoT)," ICST, 2017.

2. A. L Brown,. Vehicle Security Systems. Newnes, 1996.

3. http://www.interpol.int/Public/Vehicle/Default.asp (Feb 2010).

4. Kadar Jenayah. Statistics, www.rmp.gov.my (July 2010)

5. J Regis. B. Bates, GPRS: General Packet Radio Service, McGraw-Hill Professiona, New York, 2001.

6. Le Bodic Gwenaël, Multimedia Messaging Service: An Engineering Approach to MMS, Wiley; 1 edition, Washington, 2003.

7. Clare Churcher, Beginning Database Design: From Novice to Professional, Apress, Los Angeles, 2007. 
8. Ben Forta, MySQL Crash Course (Sams Teach Yourself in 10 Minutes), Sams, New York, 2005.

9. Nagaraj, B., and P. Vijayakumar. "Evolutionary computation based controller tuning-a comparative approach." Int J Indian Pulp Paper Tech Assoc 24, no. 2 (2012): 85-90.

10. A Simpson. and M L.Young, Access 2003 All-in-One Desk Referencefor Dummies, For Dummies; 1 edition, New York, 2003.

11. Product review: http://www.mikrotel.cz/html/kame.htm (July 2009)

12. A Gurevich, $\mathrm{N}$ Borisov. and $\mathrm{G}$ Milikh, Physics of Microwave Discharges: Artificially Ionized Regions in the Atmosphere, CRC; 1 edition, Singapore, 1997.

13. Product http://www.fuzing.com/vli/00132281c200/NP1NP4_GPR. (July 2009)

14. M Emily. Harwood, Digital CCTV: A Security Professional's Guide, Butterworth-Heinemann, London, 2007..

15. N Erme and Hasmawati, Security System for an Automobile via MobilePhone, Final year project report, IIUM, Malaysia, 2004.

16. J Carl . Weisman, Essential Guide to RF and Wireless, Prentice Hall PTR; 2 edition, New York, 2002.

17. M Ariffin. and N Abd Wahid, Monitoring and Alert System for Car, Final year project report, IIUM, Malaysia, 2007.

18. G L Bodic, Mobile Messaging Technologies and Services: MMS, EMS and MMS. Wiley, New York, 2005.

19. http://www.nowsms.com/documentation/ProductDocume ntation/overvie w.htm (july 2009)

20. N. Shaoji and S.G. Haggman. "GPRS performance estimation in GSM circuit switched services and GPRS shared resource systems." Wireless Communications and Networking Conference, IEEE, 1999 .Pp 1417-1422, New Orleans, LA, USA, 1999.

21. http://garefowl.manufacturer.globalsources.com/si/60088 25952750/pdtl/ Mobile-wireless/1003820826/MMSGPRS-Modem.htm (July 2009)

22. Shihab A. Hameed, "Car Monitoring, Alerting and Tracking Model", ICCCE2010, May 2010, Malaysia

23. http://www.ecplaza.net/tradeleads/seller/4765700/magnet ic_cont acts_magnetic.html (July 2009)

24. http://www.cytron.com.my/index.asp (July 2009)

25. Noldus, Rogier. CAMEL: Intelligent Networks for the GSM, GPRS and UMTS Network, 1st edition, Wiley, 2006.

26. www.pegtech.com/rfgps.htm (July 2009)

27. Ben Forta, MySQL Crash Course (Sams Teach Yourself in 10 Minutes), Sams, New York, 2005

28. A L Brown, Vehicle Security Systems, 2nd edition, Newnes, 1996.

29. www.ikegps.com/downloads/TTFFstartup.pdf (July 2009). 